\title{
No consensus on gestational diabetes mellitus screening regimes in Sweden: pregnancy outcomes in relation to different screening regimes 2011 to 2012, a cross-sectional study
}

Maria Lindqvist ${ }^{1 *+}$, Margareta Persson ${ }^{1,2}$, Marie Lindkvist $^{3}$ and Ingrid Mogren ${ }^{1+}$

\begin{abstract}
Background: Although associated adverse pregnancy outcomes, no international or Swedish consensus exists that identifies a cut-off value or what screening method to use for definition of gestational diabetes mellitus. This study investigates the following: i) guidelines for screening of GDM; ii) background and risk factors for GDM and selection to OGT; and iii) pregnancy outcomes in relation to GDM, screening regimes and levels of OGTT 2 hour glucose values.

Methods: This cross-sectional and population-based study uses data from the Swedish Maternal Health Care Register (MHCR) (2011 and 2012) combined with guidelines for GDM screening (2011-2012) from each Maternal Health Care Area (MHCA) in Sweden. The sample consisted of 184,183 women: 88,140 in 2011 and 96,043 in 2012. Chi-square and two independent samples t-tests were used. Univariate and multivariate logistic regression analyses were performed.

Results: Four screening regimes of oral glucose tolerance test (OGT) (75 g of glucose) were used: A) universal screening with a 2-hour cut-off value of $10.0 \mathrm{mmol} / \mathrm{L}$; B) selective screening with a 2-hour cut-off value of $8.9 \mathrm{mmol} / \mathrm{L} ; \mathrm{C}$ ) selective screening with a 2-hour cut-off value of $10.0 \mathrm{mmol} / \mathrm{L}$; and D) selective screening with a 2-hour cut-off value of $12.2 \mathrm{mmol} / \mathrm{L}$. The highest prevalence of GDM (2.9\%) was found with a 2-hour cut-off value of $8.9 \mathrm{mmol} / \mathrm{L}$ when selective screening was applied. Unemployment and low educational level were associated with an increased risk of GDM. The OR was 4.14 (Cl 95\%: 3.81-4.50) for GDM in obese women compared to women with $\mathrm{BMl}<30 \mathrm{~kg} / \mathrm{m}^{2}$. Women with non-Nordic origin presented a more than doubled risk for GDM compared to women with Nordic origin ( $O R=2.24 ; \mathrm{Cl} 95 \%$ : 2.06-2.43). Increasing OGTT values were associated with increasing risks of adverse pregnancy outcomes.

Conclusions: There was no consensus regarding screening regimes for GDM from 2011 through 2012 when four different regimes were applied in Sweden. Increasing levels of OGTT 2-hour glucose values were strongly associated with adverse pregnancy outcomes. Based on these findings, we suggest that Sweden adopts the recent recommendations of the International Association of Diabetes and Pregnancy Study Group (IADPSG) concerning the performance of OGTT and the diagnostic criteria for GDM.
\end{abstract}

\footnotetext{
* Correspondence: maria.lindqvist@obgyn.umu.se

${ }^{\dagger}$ Equal contributors

'Department of Clinical Sciences, Obstetrics and Gynecology, Umeå

University, Umeå, Sweden

Full list of author information is available at the end of the article
} 


\section{Background}

Gestational diabetes mellitus (GDM), one of the most common metabolic disorders complicating pregnancy, is defined as any degree of glucose intolerance with onset or first recognition during pregnancy, and that is not considered manifest diabetes mellitus type 2 [1]. Risk factors for GDM are family history of diabetes mellitus type 2 (DM2), previous GDM, macrosomic infant (defined as 4500 grams or more), BMI $\geq 30 \mathrm{~kg} / \mathrm{m}^{2}$ [2], unexplained intrauterine fetal death, maternal age $\geq 35$ years, and immigrant status [3-5]. The results from the Hyperglycemia and Adverse Pregnancy Outcome (HAPO) study show that higher maternal glucose levels are associated with increased macrosomia, caesarean sections and neonatal hypoglycemia [6]. Compared to normoglycemic pregnancies, women with GDM are associated with a seven-fold increased risk of DM2 later in life [7]. Offspring of women with GDM pregnancies have increased risk of obesity, glucose intolerance, and diabetes mellitus in puberty or early adulthood, all conditions included in metabolic syndrome $[8,9]$.

The global prevalence of GDM is 7\% (1-14\% depending on diagnostic tests and the population studied) [10]. Applying the diagnostic criteria of the International Association of Diabetes and Pregnancy Study Group (IADPSG) and the international multi-centre HAPO has demonstrated significant variability of prevalences of GDM among participating countries and even among participating study centres within the same country [11]. From a global perspective, Sweden is considered a low risk country for GDM with an annual prevalence of 1 to $2.6 \%$ of this pregnancy-related disorder $[12,13]$. There is, however, no international consensus regarding how women should be screened for GDM, whether screening should be undertaken universally, or whether women who present risk factors [14] should undergo screening, i.e. selective screening. This lack of consensus persists even though it is recognized that adverse pregnancy outcomes are associated with GDM and a diagnosis of GDM results in increased medical surveillance for mother and fetus during pregnancy [15]. Therefore, it is impossible to estimate the true prevalence of GDM.

In Sweden, there is no national consensus with respect to GDM screening [16]. The International Association of Diabetes and Pregnancy Study Group (IADPSG) has presented recommendations for thresholds of GDM based on the epidemiological HAPO study [17], and these recommendations have also been adopted by the World Health Organization (WHO) [18]. The proposed criteria for GDM when using a 75-gram oral glucose tolerance test (OGTT) include a fasting plasma glucose of 5.1-6.9 $\mathrm{mmol} / \mathrm{L}(92-125 \mathrm{mg} / \mathrm{dL})$ or a 1-hour plasma glucose of $10.0 \mathrm{mmol} / \mathrm{L}(180 \mathrm{mg} / \mathrm{dL})$ or a 2 -hour plasma glucose of $8.5 \mathrm{mmol} / \mathrm{L}(153 \mathrm{mg} / \mathrm{dL})$ [17].
Antenatal care (ANC) in Sweden is free and currently organized in 43 different areas called Maternal Health Care Areas (MHCA) characterized by geographic boundaries corresponding mainly to the Swedish counties. A consultant obstetrician and a consultant midwife are responsible for the guidelines regarding maternal and fetal surveillance and medical management within each MHCA. National guidelines of surveillance during pregnancy in antenatal care have been suggested by the professional associations of obstetricians and midwives [19]; however, local guidelines may differ between MHCA $[16,19]$. The overall aim of antenatal care in Sweden is to achieve "good sexual and reproductive health for the whole population", a goal that is similar to the WHO's guidelines for sexual and reproductive health. Almost all pregnant women in Sweden register in Swedish antenatal care [19].

In the Nordic countries, there is a unique opportunity to use population-based national registers for research. Due to these unique personal data registers, data may be linked, and individuals and families can be identified in several generations. The national registers are creating unique possibilities and are a valuable source of information and matrix for clinical trials [20]. The Swedish Maternal Health Care Register (MHCR) is a national health register, and data have been collected since 1999 by midwives in antenatal care. The MHCR underwent a major revision of the included variables between 2007 and 2009 , and a new version of the register was launched in 2010. The MHCR is currently monitoring around $85 \%$ of all pregnant women (personal correspondence).

There is an ongoing discussion internationally regarding the diagnostics of GDM. However, suggestions of lowering cut-off values for GDM diagnosis, the situation of GDM screening in Sweden has not changed in the last decade and there are several regimes of screening available in clinical practice. Hence, there is an opportunity to study the outcomes of different screening regimes as to add further information to the knowledge of outcomes in relation to screening regimes.

This study, which includes data on deliveries in Sweden from January $1^{\text {st }} 2011$ to December $31^{\text {st }} 2012$, investigated the following: i) guidelines for screening of GDM; ii) background and risk factors for GDM and selection to OGTT; and iii) pregnancy outcomes in relation to GDM, screening regimes and levels of OGTT 2 hour glucose values.

\section{Methods}

This cross-sectional and population-based study uses data retrieved from the Swedish Maternal Health Care Register for 2011 and 2012 in combination with local guidelines for screening of GDM collected from each MHCA in Sweden. 
All women, irrespective of single birth or multiple births, with data registered in the MHCR between 2011 and 2012 were included in the study. The coverage of registered deliveries in the MHCR was estimated to be 81\% for 2011 and 85\% for 2012 (personal correspondence). The following variables retrieved from the MHCR were included in the study: country of origin, maternal age, parity, maternal height, maternal weight, body mass index, smoking, level of education, self-reported health, number of visits to antenatal care, use of professional interpreter at visits in ANC, treatment for psychological ill-health during pregnancy, GDM, OGTT, gestational age, delivery mode, birth weight, small for gestational age (SGA), appropriate for gestational age (AGA), and large for gestational age (LGA) [21].

Local guidelines for screening of GDM were collected from all MHCA in Sweden $(n=43)$ through an initial email request between September and October 2012. The e-mail requesting local guidelines was sent to the consultant midwife in each MHCA. The majority of guidelines were collected during the first round. For those MHCA that did not respond to the first e-mail, the consultant midwife in each MHCA was contacted by telephone or by another e-mail. Finally, guidelines for screening for GDM were collected from all MHCA in Sweden. Similarities and differences in the guidelines were compared. All local guidelines for screening GDM were unchanged during the study period (2011 to 2012).

\section{Selective screening for GDM based on risk factors}

Since 1990, Sweden has officially used the recommendations developed by the European Association for the Study of Diabetes for screening for GDM. Both universal and selective screening regimes stipulate a 75-g glucose load and the two-hour value of the capillary plasma glucose for the diagnosis. However, there is no national consensus regarding the threshold for definition of GDM in Sweden, so it varies among the different MHCA. Presently, there are two national approaches for screening for GDM: one universal screening approach where all pregnant women are offered an OGTT and one selective screening approach based on specified risk factors in the local guideline. The risk factor approach (i.e., selective screening) is used by approximately $89 \%$ of the MHCA in Sweden (personal communication). The risk factors that indicate a need for screening for GDM include family history of diabetes mellitus type 2 (DM2), GDM, macrosomic infant (defined as 4500 grams or more) or stillbirth in previous pregnancy, BMI $\geq 30 \mathrm{~kg} / \mathrm{m}^{2}$, and non-European nationality. The risk factors during pregnancy indicating an OGTT are accelerating fetal growth, polyhydramniosis, and elevated random capillary plasma glucose. Both universal and selective screening regimes for the diagnostic procedures stipulate the use of a 75-g glucose load and the 2-hour value of the capillary plasma glucose. One-third of the MHCA also uses fasting glucose as a diagnostic criterion for GDM.

\section{Definitions of background and outcome variables}

Maternal age was defined as age at delivery. Parity was defined as total number of deliveries (including the index pregnancy in the register). Maternal height $(\mathrm{cm})$, and maternal weight in early pregnancy $(\mathrm{kg})$ were selfreported by the pregnant woman. Body mass index (BMI) was calculated with the formula BMI $\mathrm{kg} / \mathrm{m}^{2}$. The different BMI groups were defined according to WHO's definition of BMI: underweight: $<18.5 \mathrm{~kg} / \mathrm{m}^{2}$; normal range: $18.5-24.99 \mathrm{~kg} / \mathrm{m}^{2}$; overweight: $25-29.99 \mathrm{~kg} / \mathrm{m}^{2}$; obesity class 1: $30-34.99 \mathrm{~kg} / \mathrm{m}^{2}$; obesity class 2 : $35-$ $39.99 \mathrm{~kg} / \mathrm{m}^{2}$; and obesity class $3: \geq 40 \mathrm{~kg} / \mathrm{m}^{2}$. Smoking at three months before pregnancy and at the first antenatal visit was reported. Level of education was defined as elementary school, high school, and university. Self-reported health was reported by the woman during early pregnancy and divided into five categories: very good, good, either good or poor, poor, and very poor health. Gestational diabetes mellitus (GDM) was defined as any degree of glucose intolerance with onset or first recognition during pregnancy. The cut-off values $-8.9 \mathrm{mmol} / \mathrm{L}$, $10.0 \mathrm{mmol} / \mathrm{L}$, and $12.2 \mathrm{mmol} / \mathrm{L}$ - for the diagnosis of GDM were determined by the MHCA. OGTT (75 g 2-two-hour oral glucose tolerance test) was used to diagnose GDM in all parts of Sweden. For analysis, the OGTT glucose values were categorised into two different sets. The first set of categories was as follows: $<7.5 \mathrm{mmol} / \mathrm{L}, \quad 7.5-8.8 \mathrm{mmol} / \mathrm{L}, \quad 8.1-8.9 \mathrm{mmol} / \mathrm{L}, 9.0$ $9.9 \mathrm{mmol} / \mathrm{L}, 10.0-12.1 \mathrm{mmol} / \mathrm{L}$, and $\geq 12.2 \mathrm{mmol} / \mathrm{L}$. The second set used the categories defined by IADPSG, which define a normal OGTT as a glucose value of $<8.5 \mathrm{mmol} / \mathrm{L}$, GDM (i.e., glucose value) between 8.5 and $11.0 \mathrm{mmol} / \mathrm{L}$, and manifest diabetes mellitus type 2 (i.e., glucose value $\geq 11.1 \mathrm{mmol} / \mathrm{L}$ ) [17]. Delivery mode was reported as either as vaginal non-instrumental, vaginal instrumental, elective caesarean section, or emergency caesarean section. Birth weight was reported in grams. In calculations of birth weight, the birth weight of single births were included as well as birth weight of first child of duplex or triplex pregnancy. Small for gestational age (SGA), appropriate for gestational age (AGA), and large for gestational age (LGA) were calculated using Marsal's curve [21].

Ethical approval from the Ethical Review Board in Umeå was granted 2012 (Dno. 2012-407-3IM).

\section{Statistical analysis}

Two-independent samples t-tests were used to test differences of parametric data, and non-parametric twoindependent samples tests were used to test differences 
of categorical variables. Univariate and multivariate logistic regression analyses were performed and presented with odds ratios (OR) and their 95\% confidence intervals (CI) where different models were demonstrated. The population attributable proportion (PAP) was calculated for specified exposures using the formula PAP $=p(R R-1) /$ $[1+p(R R-1)]$, where PAP is the proportion of cases in the population that should not have occurred had the exposed had the incidence of the unexposed. Statistical analysis was done using SPSS version 19.

\section{Results}

The total sample consisted of 184,183 deliveries $(88,140$ in 2011 and 96,043 in 2012). Mean maternal age and mean parity at delivery was 30.25 years and 1.8 , respectively (Table 1). Table 1 shows the background characteristics for the whole sample as well as for each year (2011 and 2012). Test of difference was calculated for 2011 vs. 2012 for all variables. The following significant $\mathrm{p}$-values were found comparing the variables for the year 2011 and the year 2012: maternal age in years $(p=0.032)$, weight $(0.005)$, and BMI $(\mathrm{p}=0.001)$. Regarding performed OGTT, 2011 vs. 2012 significant p-values were found for the variables weight $(\mathrm{p}=0.001)$, BMI $(0.001)$, educational level $(\mathrm{p}=0.003)$, employment status $(\mathrm{p}=0.012)$, number of visits to ANC ( $=0.011)$, SRH $(p=0.001)$, reported smoking three months before pregnancy $(\mathrm{p}=0.001)$, and reported smoking at first visit $(\mathrm{p}=0.001)$. The variables are presented in Table 1.

\section{Four screening regimes for diagnostics of GDM in Sweden}

Nationally, four GDM screening regimes were used between 2011 and 2012, using different capillary plasma glucose values for the diagnosis of GDM. Accordingly, there was no national consensus regarding screening and diagnosis of GDM in Sweden (Table 2). Four schemes for GDM screening were followed: A) universal screening with a 2-hour cut-off value of $10.0 \mathrm{mmol} / \mathrm{L}$; B) selective screening with a 2-hour cut-off value of $8.9 \mathrm{mmol} / \mathrm{L}$; C) selective screening with a 2-hour cut-off value of $10.0 \mathrm{mmol} / \mathrm{L}$; and $\mathrm{D}$ ) selective screening with a 2-hour cut-off value of $12.2 \mathrm{mmol} / \mathrm{L}$. The OGTT 2-hour cut-off value of $12.2 \mathrm{mmol} / \mathrm{L}$ as diagnosis for GDM in the fourth category was regarded as diagnosis of manifest diabetes mellitus in the majority of the MHCA in Sweden. Most pregnant women (56.8\%) in Sweden underwent selective screening of GDM with a 2-hour cut-off glucose value of $10.0 \mathrm{mmol} / \mathrm{L}$. Fewer pregnant women (11.3\%) were offered universal screening with the same criteria for diagnosis $(10 \mathrm{mmol} / \mathrm{L})$. In total, $88.7 \%$ of pregnant women in Sweden underwent selective screening. The background factors family history of diabetes mellitus type 2, previous GDM, macrosomic infant $(\geq 4.5 \mathrm{~kg})$, and $\mathrm{BMI}>30 \mathrm{~kg} / \mathrm{m}^{2}$ were used by $81 \%$ of the MHCA as indicators for OGTT during pregnancy. Other indicators were unexplained intrauterine fetal death, maternal age more than 35 years, and immigrant status. Among the MHCA, only four had immigrant status as an indicator for OGTT. A vast majority of MHCA (81\%) used BMI $>30$ or 35 as an indicator for OGTT. The most prevalent risk indicator for OGTT was elevated random plasma glucose $(8.0-9.0 \mathrm{mmol} / \mathrm{L})$, which was presented in all the MHCA using selective screening.

\section{Prevalences of OGTT and GDM}

Table 2 presents maternal background characteristics, prevalences of OGTT, GDM, and birth weight (mean, minimum, and maximum) in relation to current regimes of screening of GDM between 2011 and 2012. As expected, the prevalence of OGTT was highest (93.6\%) in the MHCA that offered pregnant women universal screening of GDM, and the prevalence of OGTT was lowest $(6.8 \%)$ in the screening category with a 2-hour cut-off value of $12.2 \mathrm{mmol} / \mathrm{L}$ as criteria for GDM (Table 2). The lowest prevalence of OGTT was for women younger than 19 years old (17.6\%). The highest prevalence was for women 40 years old or older (24.0\%) (Table 1). As body mass index increased, the prevalence of OGTT increased. The lowest prevalence was for women in the lowest BMI category (BMI $<18.5 \mathrm{~kg} / \mathrm{m}^{2}$; $13.6 \%$ ), and the highest prevalence was for women with a BMI between 35 and $39.99 \mathrm{~kg} / \mathrm{m}^{2}(65.7 \%)$ and women with BMI 40 or higher $(73.3 \%)$ (Table 1). The highest prevalence of GDM (2.9\%) was found in the areas where selective screening was applied with an OGTT 2-hour value of $8.9 \mathrm{mmol} / \mathrm{L}$ as criteria for diagnosis of GDM (Table 2). As shown in Table 1, the prevalence of GDM increased with increasing values in categories of maternal age, BMI, and parity. Furthermore, the prevalence of GDM increased in women who had a low educational level, who were unemployed, and who rated their health as "either good or poor" or "very poor" compared to women with higher educational level, women who were employed, and women who rated their health as "good or very good" (Table 1 ).

\section{Population attributable proportion}

To calculate the population attributable proportion, we selected the two screening regimes universal screening "A" (Table 2) and selective screening "C" (Table 2) (i.e., two categories using the same 2-hour capillary plasma glucose value of $10 \mathrm{mmol} / \mathrm{L}$ for diagnosis of GDM). For each screening regime, the PAP for GDM was calculated for the exposures obesity, increased maternal age (i.e., maternal age 35 years or more), and non-Nordic origin. For the screening regime "A", 20\%, $14 \%$, and $22 \%$ of GDM cases could be attributed to 
Table 1 Characteristics of subjects and test of difference between specified categories

\begin{tabular}{|c|c|c|c|c|c|}
\hline Variables $^{a}$ & $\begin{array}{l}\text { All subjects } \\
2011-2012 \mathrm{~N}(\%)\end{array}$ & $\begin{array}{l}\text { Subjects } \\
2011 \text { n (\%) }\end{array}$ & $\begin{array}{l}\text { Subjects } \\
2012 \text { n (\%) }\end{array}$ & $\begin{array}{l}\text { OGTT } \\
\text { 2011-2012 N (\%) }\end{array}$ & $\begin{array}{l}\text { GDM } \\
\text { 2011-2012 N (\%) }\end{array}$ \\
\hline Maternal (yrs) & $184130(99.8)$ & 88016 (99.7) & $96025(99.9)$ & $38302(99.8)$ & 2579 (99.8) \\
\hline Mean(SD) & $30.25(5.3)$ & $30.27(5.3)$ & $30.23(5.3)$ & $30.36(5.4)$ & $31.86(5.5)$ \\
\hline Min-Max & $13-57$ & $13-53$ & $13-57$ & $15-54$ & $16-53$ \\
\hline \multicolumn{6}{|l|}{ Maternal age } \\
\hline$\leq 19$ & $2688(1.5)$ & 1369 (1.6) & $1319(1.4)$ & 469 (17.6) & $23(0.9)$ \\
\hline $20-24$ & $25212(13.7)$ & $11990(13.8)$ & $13222(13.8)$ & $5293(21.2)$ & $239(1.0)$ \\
\hline $25-29$ & $53971(29.3)$ & $25570(29.0)$ & $28393(29.6)$ & $11257(21.0)$ & $618(1.1)$ \\
\hline $30-34$ & 61706 (33.5) & $29463(33.4)$ & $32243(33.6)$ & $12432(20.3)$ & 837 (1.4) \\
\hline $35-39$ & $33225(18.0)$ & $16215(18.4)$ & $17010(17.7)$ & 7130 (21.5) & $642(1.9)$ \\
\hline$\geq 40$ & $738(4.0)$ & $3490(4.0)$ & $3838(4.0)$ & $1748(24.0)$ & $220(3.0)$ \\
\hline Parity & $181292(98.4)$ & $86189(96.0)$ & $95103(98.2)$ & 37603(96.8) & 2548 (97.3) \\
\hline 1 & $79250(43.7)$ & $37569(43.6)$ & $41681(43.8)$ & $15493(19.7)$ & $949(1.2$ \\
\hline 2 & $67902(37.5)$ & $32340(37.5)$ & $35562(37.4)$ & $14130(20.9)$ & 861 (1.3) \\
\hline$\geq 3$ & $34140(18.8)$ & $16280(18.9)$ & $17860(18.8)$ & 7980 (22.8) & $738(2.9)$ \\
\hline Gest age $^{b c}$ & $180822(98.2)$ & $86434(97.9)$ & $94388(98.1)$ & $37684(97.2)$ & 2513 (97.6) \\
\hline Pre-term & $9838(5.4)$ & $4689(5.4)$ & $5149(5.5)$ & 1914 (19.6) & $209(2.1)$ \\
\hline Term & 156599 (86.6) & 74874 (86.6) & $81725(86.6)$ & $32714(21.0)$ & 2208 (1.4) \\
\hline Post-term & $14385(8.0)$ & $6871(8.0)$ & $7514(8.0)$ & $3056(21.4)$ & $96(0.7)$ \\
\hline Weight (kg) & $179343(97.4)$ & $85359(97.9)$ & $93984(97.9)$ & 37062 (96.8) & 2510 (97.3) \\
\hline Mean (SD) & $68.50(13.7)$ & $68.40(13.6)$ & $68.59(13.7)$ & $75.45(17.7)$ & 7704 (18.6) \\
\hline Min-Max & 29-183 & 29-183 & $30-183$ & $36-183$ & $40-163$ \\
\hline Height (cm) & 180124 (97.8) & $85764(97.3)$ & $94360(98.2)$ & $37762(97.3)$ & 2519 (97.7) \\
\hline Mean (SD) & $166.2(6.5)$ & $166.2(6.5)$ & $166.2(6.5)$ & $166.2(6.6)$ & $163.8(6.8)$ \\
\hline Min-Max & 113-196 & 113-193 & 113-196 & 133-195 & $133-187$ \\
\hline BMI $\left(k g / m^{2}\right)^{d}$ & $178723(97.0)$ & $85046(97.5)$ & & $36967(96.8)$ & 2496(96.8) \\
\hline Mean (SD) & $24.78(4.6)$ & $24.74(4.6)$ & $24.82(4.7)$ & $27.29(6.1)$ & $28.70(6.3)$ \\
\hline Min-max & $13.6-62.6$ & $13.8-62.1$ & $13.6-60.0$ & $13.6-62.1)$ & $16.0-60.0$ \\
\hline BMI early pregnancy & $178723(97.0)$ & $85046(97.5)$ & $93677(96.7)$ & $36967(96.5)$ & 2496(96.8) \\
\hline$<18.5$ & $4329(2.4)$ & $2031(2.4)$ & $2298(2.5)$ & $586(13.6)$ & $23(0.5)$ \\
\hline $18.5-24.99$ & $1056679(59.1)$ & $50622(59.5)$ & $55057(58.8)$ & $15633(14.9)$ & $789(0.7)$ \\
\hline $25-29.99$ & $45667(25.6)$ & $21641(25.4)$ & $24026(25.6)$ & $9285(20.4)$ & $754(1.7)$ \\
\hline $30-34.99$ & $16126(9.0)$ & $7537(8.8)$ & $8589(9.2)$ & $6793(42.4)$ & $511(3.2)$ \\
\hline $35-39.99$ & $5117(2.9)$ & $2379(2.8)$ & $2738(2.9)$ & $3327(65.7)$ & $285(5.8)$ \\
\hline$\geq 40$ & $1805(1.0)$ & $836(1.0)$ & $969(1.0)$ & $1313(73.3)$ & $134(7.4)$ \\
\hline Educational level & 151600 (82.3) & $70638(79.5)$ & $80962(84.0)$ & $32183(82.3)$ & $2003(76.5)$ \\
\hline Elementary school & $13532(8.9)$ & $6662(9.4)$ & $6870(8.5)$ & $3239(24.1)$ & $309(2.4)$ \\
\hline High school & $60481(39.9)$ & $27821(39.4)$ & $32660(40.3)$ & $14263(23.7)$ & $904(1.5)$ \\
\hline University & $77587(51.2)$ & $36155(51.2)$ & $41432(51.2)$ & $14681(19.0)$ & $790(1.0)$ \\
\hline Employment status & $179628(97.5)$ & $85165(94.6)$ & $94463(98.0)$ & $37330(96.1)$ & 2501 (95.6) \\
\hline Employed $^{e}$ & 159566 (88.8) & $75669(88.8)$ & $83897(88.8)$ & $32805(21.9)$ & 2057 (1.6) \\
\hline Unemployed $^{f}$ & $20062(11.2)$ & $9496(11.2)$ & $10566(11.2)$ & $4525(22.9)$ & $444(2.4)$ \\
\hline Country of origin & $184132(100)$ & $88140(100)$ & $96043(100)$ & $38308(97.6)$ & $2579(97.2)$ \\
\hline Sweden & $144563(78.5)$ & $70376(79.8)$ & $74187(77.2)$ & $29637(20.6)$ & $1613(1.1)$ \\
\hline
\end{tabular}


Table 1 Characteristics of subjects and test of difference between specified categories (Continued)

\begin{tabular}{|c|c|c|c|c|c|}
\hline Nordic countries ${ }^{9}$ & $1445(0.8)$ & $613(0.7)$ & $832(0.9)$ & $350(24.6)$ & $23(1.7)$ \\
\hline Other countries & $34134(18.5)$ & $17151(19.5)$ & $21024(21.9)$ & $8318(22.4)$ & $943(2.8)$ \\
\hline Visits at $A N C^{h}$ & $182137(98.9)$ & $86822(98.6)$ & $95315(99.2)$ & 37917(99.0) & $2534(98.3)$ \\
\hline Mean: & $8.8(2.4)$ & $8.8(2.4)$ & $8.7(2.7)$ & $9.0(2.4)$ & $9.3(3.0)$ \\
\hline Max-min: & $1-29$ & $2-26$ & $1-24$ & $1-29$ & $1-26$ \\
\hline $\mathrm{SRH}^{\mathrm{i}}$ & $153227(83.2)$ & $70633(79.1)$ & $82594(85.7)$ & $32442(83.3)$ & $2102(80.3)$ \\
\hline Very good & $44310(28.9)$ & $19838(28.1)$ & $24472(29.6)$ & 8484 (19.2) & $422(1.0)$ \\
\hline Good & $89740(58.6)$ & $41299(58.5)$ & $48441(58.6)$ & $19650(22.0)$ & $1317(1.5)$ \\
\hline Either good or poor & $13755(9.0)$ & $6793(9.6)$ & $6962(8.4)$ & $3142(23.0)$ & $260(1.9)$ \\
\hline Poor & $4371(2.9)$ & $2174(3.1)$ & $2197(2.7)$ & $950(21.8)$ & $82(1.9)$ \\
\hline Very poor & $1051(0.7)$ & $529(0.7)$ & $522(0.6)$ & $216(20.7)$ & $21(2.0)$ \\
\hline Smoking 3 months ${ }^{j}$ & $182532(99.1)$ & $75316(98.8)$ & $81797(99.2)$ & $38305(97.5)$ & 2579(97.6) \\
\hline No smoking & $157113(85.2)$ & $75316(85.5)$ & $81797(86.1)$ & $31718(20.3)$ & $2167(1.4)$ \\
\hline Smoking & $25419(14.8)$ & $12134(14.5)$ & $13285(13.9)$ & $5976(23.7)$ & $387(1.6)$ \\
\hline Smoking first visit & $182619(99.0)$ & $84134(94.2)$ & $96043(98.5)$ & $38305(97.6)$ & 2579 (97.6) \\
\hline No smoking & $172082(94.3)$ & $82451(94.2)$ & $89631(94.1)$ & $35139(20.5)$ & $2380(1.5)$ \\
\hline Smoking & $10537(5.7)$ & $5062(5.7)$ & $5475(5.9)$ & $2578(24.6)$ & $174(1.7)$ \\
\hline
\end{tabular}

${ }^{\mathrm{a}}$ For each specified variable, $\mathrm{n}$ and $\%$ are presented.

${ }^{b}$ Gestational age calculated using the WHO's guidelines.

${ }^{\mathrm{c}}$ Pre-term $=22+0-36+6$, Term $=37+0-41+6$, Post-term $=42+0-43+6$ (weeks).

dBody mass index (BMI).

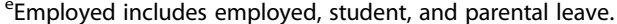

fUnemployed includes unemployed, sick leave, and other.

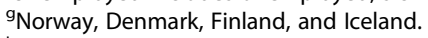

${ }^{\mathrm{h}}$ Antenatal care unit (ANC).

iSelf-rated health (SRH).

${ }^{j}$ Smoking three months before pregnancy.

obesity, increased maternal age, and non-Nordic origin, respectively. The corresponding PAPs for screening regime "C" were $31 \%, 17 \%$, and $19 \%$ of GDM cases that could be attributed to obesity, increased maternal age, and non-Nordic origin, respectively.
Maternal characteristics and pregnancy outcomes in relation to screening regimes

Maternal characteristics and pregnancy outcomes such as maternal age, maternal BMI, birth weight, large for gestational age, and small for gestational age are presented in

Table 2 Maternal characteristics and specific outcomes in relation to four screening regimes for gestational diabetes mellitus (GDM) in Sweden between 2011 and 2012

\begin{tabular}{|c|c|c|c|c|c|c|c|}
\hline Variables & $\begin{array}{l}\text { All } \\
\text { n (\%) }\end{array}$ & $\begin{array}{l}M^{a} \text { (yrs) } \\
\text { Mean } \\
\text { Min-max }\end{array}$ & $\begin{array}{l}\text { Height }(\mathrm{cm}) \\
\text { Mean } \\
\text { Min-max }\end{array}$ & $\begin{array}{l}\text { BMI }^{\mathbf{b}} \\
\text { Mean } \\
\text { Min-max }\end{array}$ & $\begin{array}{l}\mathrm{BMI}^{\mathrm{b}} \\
\geq 30 \\
\mathrm{n}(\%)\end{array}$ & $\begin{array}{l}\text { OGTT }^{c} \\
\text { n (\%) }\end{array}$ & $\begin{array}{l}\text { GDM } \\
\text { n (\%) }\end{array}$ \\
\hline \multirow[t]{2}{*}{ A. Universal screening $10.0 \mathrm{mmol} / \mathrm{L}^{\mathrm{d}}$} & 20822 (11.3) & 30.0 & 166.4 & 25.04 & $2784(14.1)$ & 19294 (93.6) & $456(2.2)$ \\
\hline & & $15-49$ & $140-190$ & $13.63-55.98$ & & & \\
\hline \multirow[t]{2}{*}{ B. Selective screening $8.9 \mathrm{mmol} / \mathrm{L}^{\mathrm{d}}$} & $8634(4.7)$ & 29.8 & 166.4 & 24.99 & $1110(13.4)$ & $1674(19.6)$ & $252(2.9)$ \\
\hline & & $15-49$ & $135-190$ & $13.82-56.65$ & & & \\
\hline \multirow[t]{2}{*}{ C. Selective screening $10.0 \mathrm{mmol} / \mathrm{L}^{\mathrm{d}}$} & $104688(56.8)$ & 29.8 & 166.2 & 25.04 & $14523(14.2)$ & $13934(13.4)$ & $1494(1.4)$ \\
\hline & & $13-54$ & $113-195$ & $13.90-62.06$ & & & \\
\hline \multirow[t]{2}{*}{ D. Selective screening $12.2 \mathrm{mmol} / \mathrm{L}^{\mathrm{d}}$} & $50039(27.2)$ & 31.4 & 166.2 & 24.11 & 4631 (9.6) & 3403 (6.8) & $377(0.8)$ \\
\hline & & $14-57$ & $123-196$ & $13.97-56.40)$ & & & \\
\hline
\end{tabular}

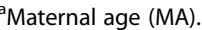

${ }^{\mathrm{b}}$ Body mass index (BMI) kg/m².

'Oral glucose tolerance test (OGTT).

${ }^{\mathrm{d} C u t-o f f}$ value. 
Table 1 for the four different screening regimes and in relation to the subcategories of GDM and non-GDM within each screening regime. The levels of maternal BMI among non-GDM cases were similar between regimes with the exception of non-GDM cases in the category where selective screening with a cut-off value of $12.2 \mathrm{mmol} / \mathrm{L}$ was applied, which presented a lower BMI-value (Table 3). Overall, the highest prevalence of LGA cases (20.6\%) was found among women with GDM in the MHCA where selective screening and a 2-hour cut-off value of $12.2 \mathrm{mmol} / \mathrm{L}$ for diagnosis of GDM was applied (Table 3).

\section{Pregnancy outcomes in relation to OGTT 2-hour glucose values}

Increasing OGTT 2-hour glucose values were associated with increasing prevalences of adverse pregnancy outcomes such as instrumental vaginal delivery, caesarean section (elective CS as well as emergency CS), and large for gestational age (Table 4). Prevalences of LGA ranged from 5.7\% (OGTT 2-hour glucose value of $\leq 7.5 \mathrm{mmol} / \mathrm{L}$ ) to $15.6 \%$ (OGTT 2-hour glucose value $\geq 12.2 \mathrm{mmol} / \mathrm{L}$ ). Prevalences of SGA were fairly similar in the different categories of OGTT values, ranging from 2.0 to $2.7 \%$ (Table 4). Furthermore, we categorized the OGTT 2-hour glucose values according to the criteria defined by IADPSG and WHO. The same pattern as in Table 4 was seen with increasing prevalences of similar adverse pregnancy outcomes (Table 5).

\section{Gestational diabetes mellitus in relation to maternal characteristics}

Table 6 presents univariate and multivariate logistic regression analyses for the outcome GDM in relation to non-GDM for different background variables such as BMI, maternal age, country of origin, employment status, and educational level. Among the background variables investigated, obesity (defined as BMI $>30 \mathrm{~kg} / \mathrm{m}^{2}$ ) demonstrated the strongest impact on risk of GDM (Table 6). The OR for GDM was 4.14 (95\% CI 3.81-4.50) for women with obesity compared to women with BMI less than 30. When adjusting for age, country of birth, employment status, and educational level, the OR was moderately changed with an OR of 3.66 (95\% CI 3.314.01). Women with a non-Nordic origin had more than twice the risk for GDM in relation to women with Nordic origin (Table 6).

\section{Pregnancy outcomes in relation to gestational diabetes mellitus}

Maternal characteristics and pregnancy outcomes are presented in Table 3 in relation to the four screening regimes and the subcategories of GDM and non-GDM within each screening regime. The maternal BMI was significantly higher for GDM cases compared to non-GDM cases regardless of screening regime category. The highest mean BMI was found for GDM cases exposed to screening regime $C$ $\left(29.22 \mathrm{~kg} / \mathrm{m}^{2}\right)$ (Table 3). The prevalence of LGA was significantly higher for GDM cases in all screening regime categories. In relation to non-GDM cases in each screening regime

Table 3 Maternal characteristics and specified pregnancy outcomes in relation to categories of universal and selective screening regimes for gestational diabetes mellitus (GDM) between 2011 and 2012

\begin{tabular}{|c|c|c|c|c|c|c|c|}
\hline \multirow[t]{2}{*}{ Variables } & $\begin{array}{l}\text { Maternal age } \\
\text { (years) }\end{array}$ & Maternal BMI ${ }^{\mathrm{a}}$ & $\begin{array}{l}\text { Birth weight } \\
\text { (grams) }\end{array}$ & $\mathrm{LGA}^{\mathrm{b}}$ & $\begin{array}{l}\text { LGA/non } \\
\text { LGA }\end{array}$ & $S G A^{c}$ & \multirow{2}{*}{$\begin{array}{l}\text { SGA/non } \\
\text { LGA } \\
\text { p-value }\end{array}$} \\
\hline & Mean & Mean & Mean & n (\%) & p-value & & \\
\hline Universal screening $10.0 \mathrm{mmol} / \mathrm{L}^{\mathrm{d}}$ & & & & $890(4.4)$ & & $478(2.4)$ & \\
\hline GDM & 31.58 & 27.63 & 3540 & $46(10.5)$ & $<0.001$ & $17(3.9)$ & 0.121 \\
\hline Non GDM & 29.98 & 24.98 & 3533 & $844(4.3)$ & & $59(2.3)$ & \\
\hline Selective screening $8.9 \mathrm{mmol} / \mathrm{L}^{\mathrm{d}}$ & & & & $382(4.7)$ & & $218(2.7)$ & \\
\hline GDM & 31.67 & 28.27 & 3567 & $25(10.4)$ & $<0.001$ & $7(2.9)$ & 0.588 \\
\hline Non GDM & 29.72 & 24.89 & 3555 & $352(4.4)$ & & $210(2.6)$ & \\
\hline Selective screening $10.0 \mathrm{mmol} / \mathrm{L}^{\mathrm{d}}$ & & & & $4375(4.3)$ & & $2586(2.5)$ & \\
\hline GDM & 31.71 & 29.22 & 3636 & $215(14.9)$ & $<0.001$ & $19(1.3)$ & 0.063 \\
\hline Non GDM & 29.77 & 24.98 & 3534 & $4184(4.1)$ & & $2561(2.5)$ & \\
\hline Selective screening $12.2 \mathrm{mmol} / \mathrm{L}^{\mathrm{d}}$ & & & & $1903(4.0)$ & & $1289(2.7)$ & \\
\hline GDM & 32.94 & 27.98 & 3610 & 84 (20.6) & $<0.001$ & $14(3.8)$ & 0.058 \\
\hline Non GDM & 31.39 & 24.08 & 3506 & 1819 (3.9) & & $1273(2.7)$ & \\
\hline
\end{tabular}

${ }^{\mathrm{a}}$ Body mass index (BMI) $\mathrm{kg} / \mathrm{m}^{2}$.

barge for gestational age (LGA).

'Small for gestational age (SGA).

${ }^{\mathrm{d} O G T T}$ 2-hour cut-off value. 
Table 4 Oral glucose tolerance test (OGTT) 2-hour values in categories in relation to specified pregnancy outcomes between 2011 and 2012

\begin{tabular}{|c|c|c|c|c|c|c|c|c|c|}
\hline $\begin{array}{l}\text { OGTT values in } \\
\text { categories } \\
\text { (mmol/L) }\end{array}$ & n (\%) & $\begin{array}{l}\text { Birth weight } \\
\text { (grams) } \\
\text { Mean min-max }\end{array}$ & n (\%) & n (\%) & $\begin{array}{l}\text { Vaginal non } \\
\text { instrumental } \\
\text { Delivery } n(\%)\end{array}$ & $\begin{array}{l}\text { Vaginal } \\
\text { instrumental } \\
\text { Delivery } \mathrm{n}(\%)\end{array}$ & n (\%) & Elective CS & Emergency CS \\
\hline \multirow[t]{2}{*}{$<7.5$} & 26307 (71.6) & 3594 & $1445(5.7)$ & $590(2.4)$ & $20082(76.5)$ & $1781(6.8)$ & $4388(16.7)$ & $1928(7.3)$ & $2455(9.3)$ \\
\hline & & $300-5890$ & & & & & & & \\
\hline \multirow[t]{2}{*}{$7.5-8.0$} & 3644 (9.9) & 3663 & $316(9.0)$ & $68(2.1)$ & 2646 (72.7) & $264(7.2)$ & $732(20.1)$ & $302(8.3)$ & $430(11.8)$ \\
\hline & & $345-5940$ & & & & & & & \\
\hline \multirow[t]{2}{*}{$8.1-8.9$} & $3576(9.7)$ & 3682 & 355 (10.3) & $64(2.0)$ & 2537 (71.1) & $262(7.3)$ & 770 (21.6) & $315(8.8)$ & $455(12.7)$ \\
\hline & & $990-6020$ & & & & & & & \\
\hline \multirow[t]{2}{*}{$9.01-9.9$} & $1504(4.1)$ & 3640 & $177(12.2)$ & $31(2.4)$ & $1024(68.4)$ & $105(7.0))$ & $369(24.1)$ & $157(10.4)$ & $211(14.1)$ \\
\hline & & $491-6270$ & & & & & & & \\
\hline \multirow[t]{2}{*}{$10.0-12.1$} & $1411(3.8)$ & 3620 & $198(14.8)$ & $30(2.5)$ & $917(65.2)$ & $101(7.2)$ & $388(27.6$ & $174(12.4)$ & $214(15.4)$ \\
\hline & & $512-5955$ & & & & & & & \\
\hline \multirow[t]{2}{*}{$\geq 12.20$} & $310(0.8)$ & 3619 & $46(15.6)$ & $7(2.7)$ & $188(60.8)$ & $24(7.8)$ & $97(31.4)$ & $44(12.7)$ & $57(17.8)$ \\
\hline & & $1103-5540$ & & & & & & & \\
\hline
\end{tabular}

atarge for gestational age (LGA).

${ }^{\mathrm{b}}$ Small for gestational age (SGA).

'Vacuum extraction or forceps.

${ }^{\mathrm{d}}$ Ceasarean section (CS).

category, the LGA prevalences were more than doubled in screening regimes $\mathrm{A}$ and $\mathrm{B}$, more than three times higher in screening regime $\mathrm{C}$, and five times higher in screening regime $\mathrm{D}$ (Table 3 ). The highest mean birth weight was demonstrated for GDM cases in screening regime $C$ (3636 g) (Table 3). There was a significantly increased risk of CS delivery in the group of GDM cases compared with non-GDM cases $(\mathrm{OR}=1.90,95 \%$ CI 1.74-2.07). However, there was no statistically significant difference between elective CS or emergency CS regarding GDM ( $p=0.169)$.

\section{Large for gestational age in relation to maternal} characteristics

Large for gestational age fetus was strongly related to maternal obesity $(\mathrm{BMI}>30)$, with an OR of 2.46 and
95\% CI 2.33-2.60. When adjusting for maternal age, the OR for LGA moderately changed with an OR of 2.44 (95\% CI 2.31-2.58). Furthermore, when adjusting for screening regime category, the OR was only slightly altered (OR 2.38, 95\% CI 2.25-2.54). Non-Nordic origin demonstrated a protecting effect for LGA (OR 0.75; 95\% CI 0.71-0.80).

\section{Discussion}

Between 2011 and 2012 there was no national consensus regarding screening regimes of GDM in Sweden, and this situation is still prevailing. In this population-based cross-sectional study, we found that four screening and diagnostic regimes of GDM were applied in Sweden. The highest prevalence of OGTT (93.6\%) was seen in

Table 5 Oral glucose tolerance test (OGTT) 2-hour values in categories in relation to specified pregnancy outcomes between 2011 and 2012

\begin{tabular}{|c|c|c|c|c|c|c|c|c|c|}
\hline $\begin{array}{l}\text { OGTT values in } \\
\text { categories } \\
(\mathrm{mmol} / \mathrm{L})\end{array}$ & n (\%) & $\begin{array}{l}\text { Birth weight } \\
\text { (grams) } \\
\text { Mean min-max }\end{array}$ & n (\%) & n (\%) & $\begin{array}{l}\text { Vaginal non } \\
\text { instrumental } \\
\text { Delivery n (\%) }\end{array}$ & $\begin{array}{l}\text { Vaginal } \\
\text { instrumental } \\
\text { Delivery n (\%) }\end{array}$ & n (\%) & Elective CS & Emergency CS \\
\hline \multirow[t]{2}{*}{$<8.5$} & 31974 (87.0) & 3605 & $1940(6.2)$ & $696(2.2)$ & $24162(75.7)$ & $2201(6.9)$ & $5548(17.4)$ & $2392(7.8)$ & 3156 (9.6) \\
\hline & & $300-5964$ & & & & & & & \\
\hline \multirow[t]{2}{*}{$8.5-11.0$} & $4082(11.1)$ & 3661 & $474(11.8)$ & $76(1.9)$ & 2799 (68.8) & $285(11.2)$ & $987(24.2)$ & $433(10.6)$ & 554 (13.6) \\
\hline & & $491-6270$ & & & & & & & \\
\hline \multirow[t]{2}{*}{$\geq 11.1$} & $696(1.9)$ & 3646 & $124(18.3)$ & $18(2.7)$ & $433(62.5)$ & $51(7.4)$ & 209 (30.2) & 95 (11.9) & $114(18.3)$ \\
\hline & & $1103-5955$ & & & & & & & \\
\hline
\end{tabular}

aLarge for gestational age (LGA).

${ }^{b}$ Small for gestational age (SGA).

'Vacuum extraction or forceps.

${ }^{\mathrm{d}}$ Ceasarean section (CS). 
Table 6 Univariate and multivariate logistic regression analysis ${ }^{\mathrm{a} b}$ for gestational diabetes mellitus (GDM) in relation to non-GDM for specified variables between 2011 and 2012

\begin{tabular}{|c|c|c|c|c|c|}
\hline Variables & Crude $O^{a}$ & $\begin{array}{l}\text { Model } 1^{b} \\
(n=178038)\end{array}$ & $\begin{array}{l}\text { Model } 2^{b} \\
(n=178038)\end{array}$ & $\begin{array}{l}\text { Model } 3^{b} \\
(n=176145)\end{array}$ & $\begin{array}{l}\text { Model } 4^{b} \\
(n=148610)\end{array}$ \\
\hline $\mathrm{BMI}^{\mathrm{C}}<30.00$ & 1 & 1 & 1 & 1 & 1 \\
\hline $\mathrm{BMI} \geq 30.00$ & $4.14(3.81-4.50)$ & $4.10(3.74-4.42)$ & $4.00(3.68-4.35)$ & $3.93(3.62-4.28)$ & $3.66(3.31-4.01)$ \\
\hline Age $<35$ & 1 & 1 & 1 & 1 & 1 \\
\hline Age $\geq 35$ & $1.79(1.15-1.95)$ & $1.72(1.58-1.87)$ & $1.71(1.57-1.86)$ & $1.71(1.57-1.86)$ & $1.60(1.59-1.93)$ \\
\hline Nordic countries ${ }^{d}$ & 1 & & 1 & 1 & 1 \\
\hline Non Nordic countries & $2.24(2.06-2.43)$ & & $2.18(2.01-2.37)$ & $2.10(1.92-2.28)$ & $2.10(1.87-2.28)$ \\
\hline Employed $^{e}$ & 1 & & & 1 & 1 \\
\hline Unemployed $^{f}$ & $1.74(1.57-1.93)$ & & & $1.27(1.14-1.42)$ & $1.20(1.10-1.36)$ \\
\hline University level ${ }^{9}$ & 1 & & & & 1 \\
\hline$<$ University level & $1.62(1.48-1.77)$ & & & & $1.34(1.21-1.47)$ \\
\hline
\end{tabular}

${ }^{a}$ Crude odds ratio.

${ }^{\mathrm{b}}$ Adjusted odds ratio and their $95 \%$ confidence intervals.

'Body mass index (BMI) kg/m².

${ }^{\mathrm{d}}$ Norway, Finland, Denmark, and Iceland.

EEmployed includes employed, student, and parental leave.

fUnemployed includes lunemployed, sick leave, and other.

${ }^{g}$ Elementary school/high school.

the MHCA that used universal screening, and the lowest prevalence of OGTT was seen in the MHCA that used selective screening with an OGTT 2-hour cut-off value of $12.2 \mathrm{mmol} / \mathrm{L}$ as criteria for GDM. The highest prevalence of GDM (2.9\%) was seen in the area where selective screening used an OGTT 2-hour cut-off value of $8.9 \mathrm{mmol} / \mathrm{L}$. Maternal obesity, maternal age more than 35 years, non-Nordic origin, and lower level of education were all prominent risk factors for GDM. Furthermore, these background variables constituted risk factors for LGA except for women with a non-Nordic origin, resulting in a decreased risk of LGA. Most pregnant women in Sweden underwent selective screening of GDM using different OGTT 2-hour cut-off values for diagnosis. Few Swedish pregnant women (11.3\%) were offered universal screening for GDM. In the MCHA with the lowest OGTT 2-hour cut-off value $(8.9 \mathrm{mmol} / \mathrm{L})$ as criteria for diagnosis of GDM, the prevalence of GDM was significantly higher $(2.9 \%)$, compared to areas that used higher OGTT 2-hour cut-off values (10.0 and $12.2 \mathrm{mmol} / \mathrm{L}$; $2.2 \%$ and $0.8 \%$ ) as criteria for GDM diagnosis.

Sweden is considered to have a rather low prevalence of GDM (i.e., around 1.4\%) [12]. Using the current screening methods and thresholds in Sweden, this study confirmed this level of GDM. Clearly, the "true level" of GDM within a specific setting depends on screening method (universal/general), the criterion for diagnosis of GDM [22], coverage of OGTT in the targeted population, the OGTT 2-hour cut-off value, and background characteristics of the pregnant population [23].

The International Association of Diabetes and Pregnancy Study Group (IADPSG) and WHO suggest the following diagnostic criteria and cut-off values for diagnosis of GDM: a fasting plasma glucose of $5.1 \mathrm{mmol} / \mathrm{L}(92 \mathrm{mg} / \mathrm{dL})$ or a 1-hour plasma glucose of $10.0 \mathrm{mmol} / \mathrm{L}(180 \mathrm{mg} / \mathrm{dL})$ or a 2-hour plasma glucose of $8.5 \mathrm{mmol} / \mathrm{L}(153 \mathrm{mg} / \mathrm{dL})$ [18]. Only a minor part $(4.7 \%)$ of Swedish pregnant women were exposed to a screening regime for diagnosing GDM at a 2-hour plasma glucose of $8.9 \mathrm{mmol} / \mathrm{L}$, which is higher than the cut-off value of $8.5 \mathrm{mmol} / \mathrm{L}$ recommended by IADPSG and WHO $[17,18]$. Furthermore, more than one quarter of Swedish women underwent selective screening regime with a 2-hour plasma glucose value of $12.2 \mathrm{mmol} / \mathrm{L}$ or more, which commonly is graded as manifest diabetes mellitus. We find this selective screening regime unacceptable. The results in our study agree with the findings in the HAPO studies, where increasing 2-hour glucose values are associated with increasing risks for adverse pregnancy outcomes $[2,6]$. In fact, a major part of the world has adopted the recommended diagnostic criteria presented by IADPSG and WHO and our suggestion is that Sweden should follow this trend as well.

The resistance to accepting IADPSG and WHO recommendation of using the OGTT 2-hour cut-off values is related to expectations of increased work load for primary health providers due to the demand of followup by health services and the issue of unproven costeffectiveness [24].

In our study, the highest prevalence of LGA (20.6\%) was found in the MHCA where selective screening with a 2-hour cut-off value of $12.2 \mathrm{mmol} / \mathrm{L}$ for GDM diagnosis was applied. This high level of LGA differs from the prevalence of LGA in other MHCA where other 
diagnostic criteria for GDM were applied, such as a 2-hour cut-off value of $10.0 \mathrm{mml} / \mathrm{L}$ (universal screening; LGA prevalence of 10.5\%) and selective screening with a 2-hour cut-off value of $8.9 \mathrm{mml} / \mathrm{L}$ (selective screening; LGA prevalence of $10.4 \%$ ).

This high level of LGA (20.6\%) might be explained by undiagnosed glucose intolerance with additional nonexposure to intervention by health care services. This situation is especially noteworthy since the mean maternal BMI $\left(24.11 \mathrm{~kg} / \mathrm{m}^{2}\right)$ in this GDM screening regime category was significantly lower ( $\mathrm{p}$-value $<0.001$ ) compared to the mean maternal BMI in the other categories of GDM screening regimes (Table 3). The non-consensus regarding OGTT 2-hour cut-off values for diagnosis of GDM and the different regimes for screening is consistent with European protocols as a whole, demonstrating inconsistencies in GDM screening practices [23].

As demonstrated by the HAPO studies, there are continuous associations between maternal glucose levels and increasing birth weight and prevalence of caesarean section $[6,14,25]$. As previously mentioned, our study's results agree with these results and demonstrate increased risks of LGA, instrumental vaginal delivery, and caesarean section in relation to increased levels of OGTT 2-hour glucose values. Increased maternal age as a risk factor for GDM has been reported previously $[3,4]$, and our study confirms this association. Low socioeconomic status as a risk factor for GDM has also been reported previously [4], a finding also confirmed by our study. We suggest that older maternal age and low socioeconomic status should be considered as indicators for performance of OGTT when using a selective screening approach. Adverse pregnancy outcomes such as CS are well known as an adverse pregnancy outcome related to GDM, an association also confirmed by our study where the prevalence of CS increased with increased OGTT 2-hour glucose values. The OR was 1.92 times higher (95\% CI 1.75-2.06) for CS compared to vaginal delivery for women with GDM compared to pregnant women without GDM. The same pattern could be seen regarding the risk of LGA. Women of non-Nordic origin presented a significant lower risk for LGA compared to women of Nordic origin (OR $0.75,95 \%$ CI $0.71-0.80$ ) and these findings have been reported previously [26].

The OR was 1.79 times higher (95\% CI 1.15-1.95) for maternal age $\geq 35$ years compared to maternal age $<35$ years. The importance of including maternal age of 35 years or more as an indicator for OGTT was supported by the PAPs values calculated for GDM for the two screening regimes "A" and "C" (see Results), showing that $14 \%$ vs. $17 \%$ could be attributed to maternal age $\geq 35$ years.

Obesity is a global epidemic and has become a public health issue due to its association with complications during pregnancy, including significant adverse conditions such as preeclampsia, GDM, LGA, stillbirth, and caesarean section $[27,28]$. In our study, obese women had a substantial increased risk of GDM (OR 4.14; CI 95\%: 3.81-4.50) compared to normal weight women.

\section{Methodological considerations}

The internal validity of data included in the Maternal Health Care Register (MHCR) has been investigated. Unpublished results have shown an overall high coverage of variables and a satisfying quality of a major part of variables included in the register (personal communication). Because the coverage in the MHCR is considered high (81\% in 2011 and 85\% in 2012; personal communication), we believe the materials to be representative of the population of pregnant women in Sweden. Data on maternal height and maternal weight in the MHCR are mostly self-reported data (personal communication). Underreporting of the true maternal weight (i.e., reporting false lower weight) might have influenced the results, resulting in an underestimation of the prevalence of obesity in the Swedish pregnant population, and accordingly an underestimation of the associations related to BMI. However, we do not consider this situation as a major source of bias.

\section{Ethical considerations}

All health national registers in Sweden, including MHCR, comply with the rules and procedures stated by The National Board of Health and Welfare in Sweden. Collection and management of patient data in health systems and health registers are regulated through the Swedish Patient Data Law. Participation in MHCR is voluntarily. Midwives in antenatal care inform pregnant women on the aims and participation of MHCR using the following strategies: a) advertisements in the waiting room at the antenatal clinic, b) written information provided if requested by the pregnant woman, and c) at registration in antenatal care the pregnant woman receives information orally from the midwife on how data are documented in the medical files and in MHCR. In a majority of the MHCA, a pregnant woman completes a form on health issues before registration in antenatal care. Furthermore, the eligible participants receive information that all results will be presented on an aggregated level, so no individual subject can be identified.

\section{Conclusions}

There was no consensus regarding screening regimes for GDM in Sweden. Increasing levels of OGTT 2-hour glucose values were strongly associated with adverse pregnancy outcomes. Applying different screening regimes and definitions of GDM in Sweden results in different procedures in clinical management of pregnant women which contributes to unequal health care. Using 2-hour 
capillary glucose does not follow international recommendations. We therefore suggest that Sweden adopts the recent recommendations outlined by IADPSG concerning the performance of OGTT and the diagnostic criteria for GDM. The results in our study further support that maternal age $\geq 35$ years of age and educational level should be regarded as risk indicators for performance of OGTT during pregnancy.

\section{Competing interests}

The authors declare that they have no competing interests.

\section{Authors' contributions}

All authors have sufficiently contributed to this study. ML, IM, MP, and MLT designed the study. ML collected the data, conducted the first analyses, and drafted the manuscript in close collaboration with IM. ML and IM performed the statistical analyses with assistance from MLT. MP and MLT contributed to the manuscript during the work process. All authors have read and approved the final manuscript.

\section{Acknowledgements}

This study was supported by grants from Umeå University and the County Council of Västerbotten. We would like to thank all the midwives for their help. In addition, we would thank all the pregnant women for sharing their pregnancy outcomes.

\section{Author details}

${ }^{1}$ Department of Clinical Sciences, Obstetrics and Gynecology, Umeå University, Umeå, Sweden. ${ }^{2}$ Dalarna University, School of Health and Social studies, Falun, Sweden. ${ }^{3}$ Department of Statistics and Department of Public Health and Clinical Medicine, Umeå University, Umeå, Sweden.

Received: 23 September 2013 Accepted: 19 May 2014

Published: 31 May 2014

\section{References}

1. American Diabetes Association: Diagnosis and classification of diabetes mellitus. Diabetes Care 2012, 35(Suppl 1):S64-S71. PubMed PMID: 22187472. Epub 2012/01/04. eng.

2. Catalano PM, McIntyre HD, Cruickshank JK, McCance DR, Dyer AR, Metzger BE, Lowe LP, Trimble ER, Coustan DR, Hadden DR, Persson B, Hod M, Oats JJN: The hyperglycemia and adverse pregnancy outcome study: associations of GDM and obesity with pregnancy outcomes. Diabetes Care 2012, 35(4):780-786. PubMed PMID: 22357187. Pubmed Central PMCID: 3308300. Epub 2012/02/24. eng

3. Carolan M, Davey MA, Biro MA, Kealy M: Maternal age, ethnicity and gestational diabetes mellitus. Midwifery 2012, 28(6):778-783. PubMed PMID: 22000676. Epub 2011/10/18. eng.

4. Schneider S, Hoeft B, Freerksen N, Fischer B, Roehrig S, Yamamoto S, Maul $\mathrm{H}$ : Neonatal complications and risk factors among women with gestational diabetes mellitus. Acta Obstet Gynecol Scand 2011, 90(3):231-237. PubMed PMID: 21306307. Epub 2011/02/11. eng.

5. Ramos-Levi AM, Perez-Ferre N, Fernandez MD, Del Valle L, Bordiu E, Bedia AR, Herraiz MA, Torrejo'n J, Calle-Pascual AL: Risk factors for gestational diabetes mellitus in a large population of women living in Spain: implications for preventative strategies. Int J Endocrinol 2012, 2012:312529. PubMed PMID: 22567006. Pubmed Central PMCID: 3332173. Epub 2012/05/ 09. eng.

6. Metzger BE, Lowe LP, Dyer AR, Trimble ER, Chaovarindr U, Coustan DR, Hadden DR, McCance DR, Hod M, McIntyre HD, Oats JJ, Persson B, Rogers MS, Sacks DA: Hyperglycemia and adverse pregnancy outcomes. N Engl J Med 2008, 358(19):1991-2002. PubMed PMID: 18463375. Epub 2008/05/09. eng.

7. Bellamy L, Casas JP, Hingorani AD, Williams D: Type 2 diabetes mellitus after gestational diabetes: a systematic review and meta-analysis. Lancet 2009, 373(9677):1773-1779. PubMed PMID: 19465232. Epub 2009/05/26. eng.
8. Moyer VA: Screening for gestational diabetes mellitus: U.S. Preventive services task force recommendation statement. Ann Intern Med 2014, PubMed PMID: 24424622.

9. Gillman MW, Rifas-Shiman S, Berkey CS, Field AE, Colditz GA: Maternal gestational diabetes, birth weight, and adolescent obesity. Pediatrics 2003, 111(3):e221-e226. PubMed PMID: 12612275.

10. American DA: Diagnosis and classification of diabetes mellitus. Diabetes Care 2014, 37(Suppl 1):S81-S90. PubMed PMID: 24357215.

11. Sacks DA, Hadden DR, Maresh M, Deerochanawong C, Dyer AR, Metzger BE, Lowe LP, Coustan DR, HOD M, Oats JJN, Persson B, Trimble ER: Frequency of gestational diabetes mellitus at collaborating centers based on IADPSG consensus panel-recommended criteria: the Hyperglycemia and Adverse Pregnancy Outcome (HAPO) Study. Diabetes Care 2012, 35(3):526-528. PubMed PMID: 22355019. Pubmed Central PMCID: 3322716

12. Berg M, Adlerberth A, Sultan B, Wennergren M, Wallin G: Early random capillary glucose level screening and multidisciplinary antenatal teamwork to improve outcome in gestational diabetes mellitus. Acta Obstet Gynecol Scand 2007, 86(3):283-290. PubMed PMID: 17364301. Epub 2007/03/17. eng.

13. Ignell $C$, Claesson $\mathrm{R}$, Anderberg $\mathrm{E}$, Berntorp $\mathrm{K}$ : Trends in the prevalence of gestational diabetes mellitus in southern Sweden, 2003-2012. Acta Obstet Gynecol Scand 2014, 93(4):420-424. PubMed PMID: 24450766.

14. Kendrick JM: Screening and diagnosing gestational diabetes mellitus revisited: implications from HAPO. J Perinat Neonatal Nurs 2011, 25(3):226-232. quiz 33-4. PubMed PMID: 21825911. Epub 2011/08/10. eng

15. Coustan DR, Lowe LP, Metzger BE, Dyer AR: The Hyperglycemia and Adverse Pregnancy Outcome (HAPO) study: paving the way for new diagnostic criteria for gestational diabetes mellitus. Am J Obstet Gynecol 2010, 202(6):654. e1-6. PubMed PMID: 20510967. Pubmed Central PMCID: 2897007. Epub 2010/06/01. eng.

16. Persson M, Winkvist A, Mogren I: [No unified guidelines concerning gestational diabetes in Sweden. Noticeable differences between screening, diagnostics and management in maternal health services]. Lakartidningen 2007, 104(45):3365-3369.

17. Metzger BE, Gabbe SG, Persson B, Buchanan TA, Catalano PA, Damm P, Dyer AR, Leiva A, Hod M, Kitzmiler JL, Lowe LP, McIntyre HD, Oats JJ, Omori Y, Schmidt MI: International association of diabetes and pregnancy study groups recommendations on the diagnosis and classification of hyperglycemia in pregnancy. Diabetes Care 2010, 33(3):676-682. PubMed PMID: 20190296. Pubmed Central PMCID: 2827530. Epub 2010/03/02. eng.

18. WHO Guidelines Approved by the Guidelines Review Committee: Diagnostic Criteria and Classification of Hyperglycaemia First Detected in Pregnancy. Geneva: WHO Guidelines Approved by the Guidelines Review Committee; 2013.

19. Mödrahälsovård, Sexuell och Reproduktiv Hälsa [Maternal Health Care, Sexual and Reproductive health] (in Swedish). (SFOG) 2008.

20. Olsen J: Register-based research: some methodological considerations. Scand J Public Health 2011, 39(3):225-229. PubMed PMID: 21427148. Epub 2011/03/24. eng.

21. Marsal K, Persson PH, Larsen T, Lilja H, Selbing A, Sultan B: Intrauterine growth curves based on ultrasonically estimated foetal weights. Acta Paediatr 1996, 85(7):843-848. PubMed PMID: 8819552.

22. Benhalima K, Mathieu C: Gestational diabetes: update of screening strategy and diagnostic criteria. Curr Opin Obstet Gynecol 2013, 25(6):462-467. PubMed PMID: 24136163

23. Buckley BS, Harreiter J, Damm P, Corcoy R, Chico A, Simmons D, Vellinga A, Dunne F: Gestational diabetes mellitus in Europe: prevalence, current screening practice and barriers to screening: a review. Diabet Med 2012, 29(7):844-854. PubMed PMID: 22150506. Epub 2011/12/14. eng.

24. Werner EF, Pettker CM, Zuckerwise L, Reel M, Funai EF, Henderson J, Thung SF: Screening for gestational diabetes mellitus: are the criteria proposed by the international association of the diabetes and pregnancy study groups cost-effective? Diabetes Care 2012, 35(3):529-535. PubMed PMID: 22266735. Pubmed Central PMCID: 3322683.

25. Metzger BE, Persson B, Lowe LP, Dyer AR, Cruickshank JK, Deerochanawong C, Halliday HL, Hennis AJ, Liley H, Ng PC, Coustan DR, Hadden DR, Hod M, Oats JJ, Trimble ER, HAPO Study Cooperative Research Group: Hyperglycemia and adverse pregnancy outcome study: neonatal glycemia. Pediatrics 2010, 126(6):e1545-e1552. PubMed PMID: 21078733. Epub 2010/11/17. eng.

26. Fadl HE, Ostlund IK, Hanson US: Outcomes of gestational diabetes in Sweden depending on country of birth. Acta Obstet Gynecol Scand 2012, 91(11):1326-1330. PubMed PMID: 22882165. 
27. Catalano PM, Ehrenberg HM: The short- and long-term implications of maternal obesity on the mother and her offspring. BJOG 2006 113(10):1126-1133. PubMed PMID: 16827826.

28. Mission JF, Marshall NE, Caughey AB: Obesity in pregnancy: a big problem and getting bigger. Obstet Gynecol Surv 2013, 68(5):389-399. PubMed PMID: 23624964

doi:10.1186/1471-2393-14-185

Cite this article as: Lindqvist et al: No consensus on gestational diabetes mellitus screening regimes in Sweden: pregnancy outcomes in relation to different screening regimes 2011 to 2012, a cross-sectional study. BMC Pregnancy and Childbirth 2014 14:185.

\section{Submit your next manuscript to BioMed Central and take full advantage of:}

- Convenient online submission

- Thorough peer review

- No space constraints or color figure charges

- Immediate publication on acceptance

- Inclusion in PubMed, CAS, Scopus and Google Scholar

- Research which is freely available for redistribution 